\title{
Editorial
}

\section{Shock and Vibration in Transportation Engineering}

\author{
Minvydas Ragulskis, ${ }^{1}$ Luis Munoz, ${ }^{2}$ Rafał Burdzik, ${ }^{3}$ Julia I. Real, \\ Wen-Hsiang Hsieh, ${ }^{5}$ and Radosław Zimroz ${ }^{6}$ \\ ${ }^{1}$ Kaunas University of Technology, LT-51368 Kaunas, Lithuania \\ ${ }^{2}$ Universidad de los Andes, Bogota 18A10, Colombia \\ ${ }^{3}$ Silesian University of Technology, 40007 Katowice, Poland \\ ${ }^{4}$ Polytechnic University of Valencia, 46022 Valencia, Spain \\ ${ }^{5}$ National Formosa University, Huwei 63245, Taiwan \\ ${ }^{6}$ Wrocław University of Technology, 50370 Wrocław, Poland \\ Correspondence should be addressed to Minvydas Ragulskis; minvydas.ragulskis@ktu.lt
}

Received 19 May 2016; Accepted 19 May 2016

Copyright ( 2016 Minvydas Ragulskis et al. This is an open access article distributed under the Creative Commons Attribution License, which permits unrestricted use, distribution, and reproduction in any medium, provided the original work is properly cited.

One of the most important fields of mechanical engineering is the transportation issue. Almost any of the mechanical objects made by humans have to provide some type of transportation task. In many cases, the transportation is the fundamental purpose and the objective of the mechanism, but transportability can also be an important part of the functionality of many complex engineering systems. Therefore, shock and vibration phenomena play an important role in a wide range of mechanical systems. The main purpose of transportation systems and its mechanisms is to provide the movement of various types of loads or passengers. Hence, the vibration of the vehicle and its components is usually perceived as a negative and unwanted effect. However, vibration signals do also serve as an ample source of information on the technical state of the systems and are commonly employed in the online and offline diagnostic systems. Shock and vibration analysis still represents a serious challenge to researchers, engineers, and constructors in the area of transportation systems. Much attention is devoted to the development of new approaches in vibration signals analysis, where the extraction of the useful information in the signal is effectively exploited for intelligent fault diagnostics and the prediction of the remaining lifetime of components. All that knowledge is exploited for the development of new solutions and for further research in the area of shock and vibration analysis in transportation engineering, what has originated the need for this special issue.
Such wide range of research on shock and vibration in transportation engineering has attracted the attention to this special issue from the International academic and engineering communities. It has attracted 52 submissions from authors from all around the world; only 15 papers have been selected and included in this special issue on shock and vibration in transportation engineering after completing a careful and rigorous peer-review process by the international experts in the appropriate fields.

The main purpose of this special issue is to present recent directions in vibration research in various branches of transportation engineering. Many of the submitted manuscripts were rather interesting, but due to the limitation of the special issue and due to the appropriateness of topics to its scope, only a small fraction of manuscripts was selected after the peer review. The present papers cover an extensive range of problems in transportation engineering.

The papers of this special issue focus on such topics as the damping of vibration, active and semiactive suspensions, vibration phenomena in transportation mechanisms, torsional oscillations, traffic noise and vibration, vibration response characteristics of transport engineering objects (bridges and tunnels), and application of signal processing for various purposes (diagnostics and fault identification). The selected papers demonstrate and emphasize the wide range of vibration research in transportation engineering. Papers of the special issue present investigations conducted 
in different means and mechanisms of transportation, such as automotive, rail, robotic, and transmission transportation systems (pipelines and stepped beams).

The content of this special issue confirms that research direction in the area of shock and vibration is and will continue to be an important field of investigation in transportation engineering. Further directions in this area could include the identification of sources and paths of the transmission of vibration in order to be able to modify the mechanisms in the early stages of the design of transportation systems. Elimination and minimization of unwanted vibrations occurring during the operation of transportation mechanisms continue being an important research direction. Evaluation and assessment of human exposure to shock and vibration in transportation systems also remains an active and important area of research.

\section{Acknowledgments}

The editors of the special issue would like to thank authors of all submitted papers.

Minvydas Ragulskis

Luis Munoz

Rafał Burdzik

Julia I. Real

Wen-Hsiang Hsieh

Radosław Zimroz 


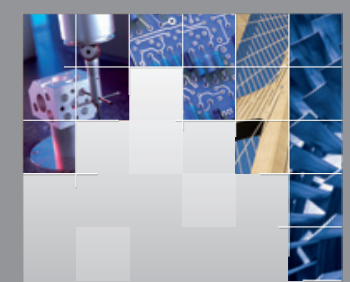

\section{Enfincering}
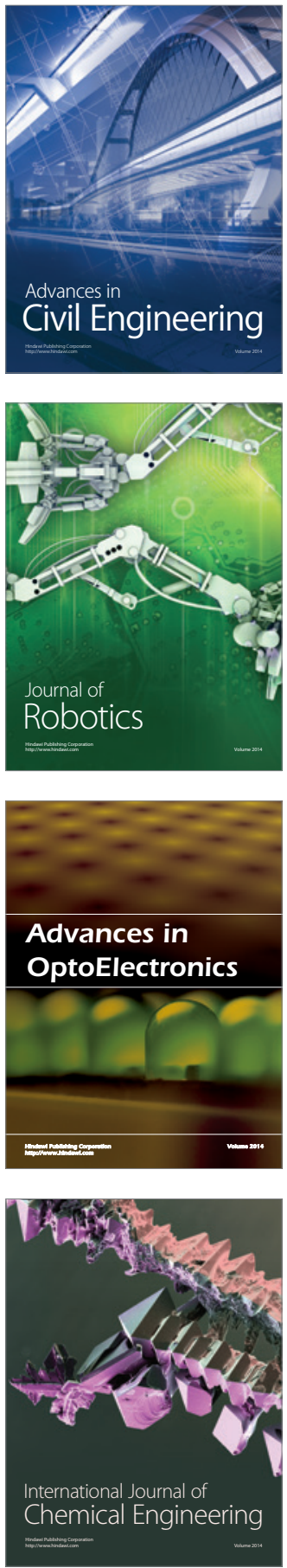

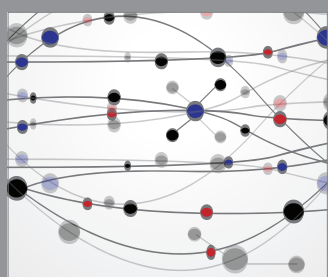

The Scientific World Journal

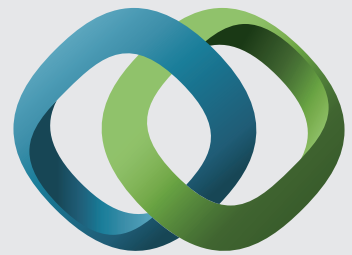

\section{Hindawi}

Submit your manuscripts at

http://www.hindawi.com
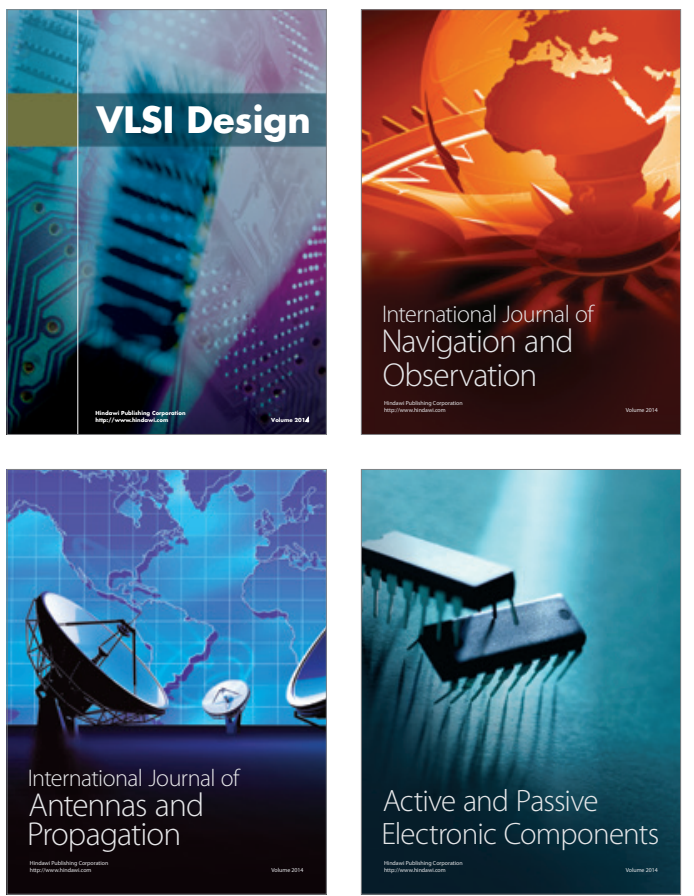
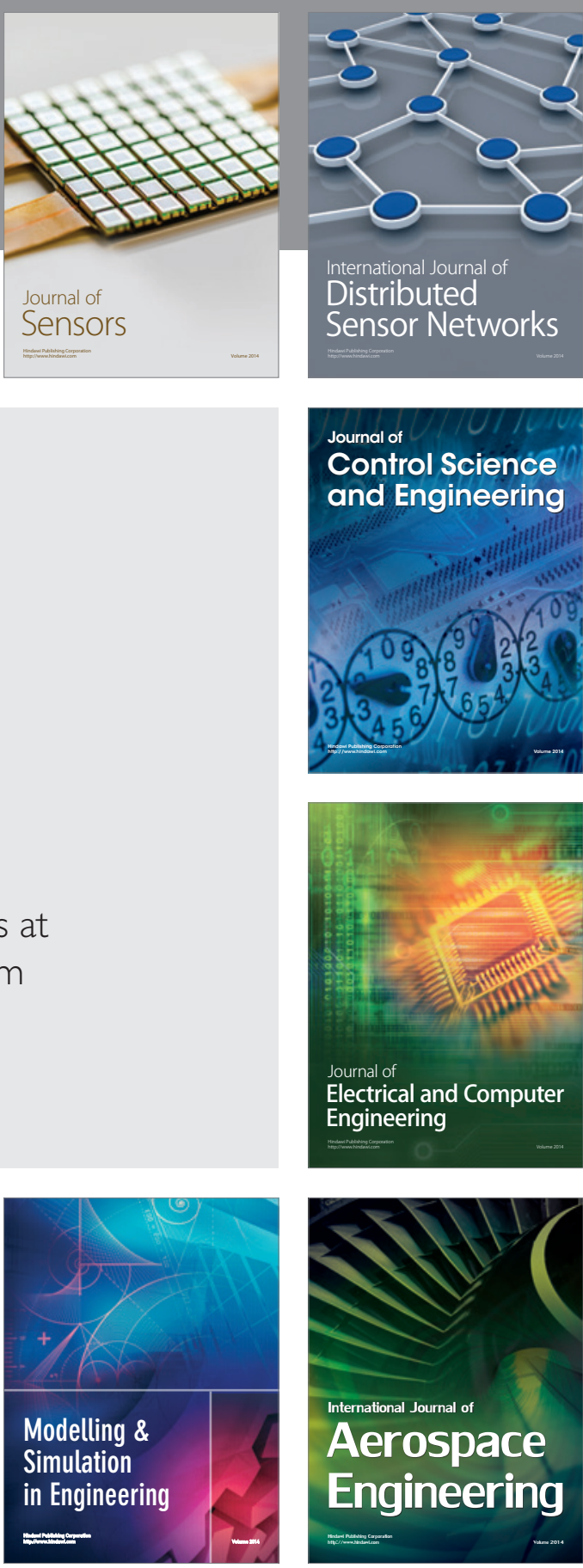

International Journal of

Distributed

Sensor Networks

Journal of

Control Science

and Engineering
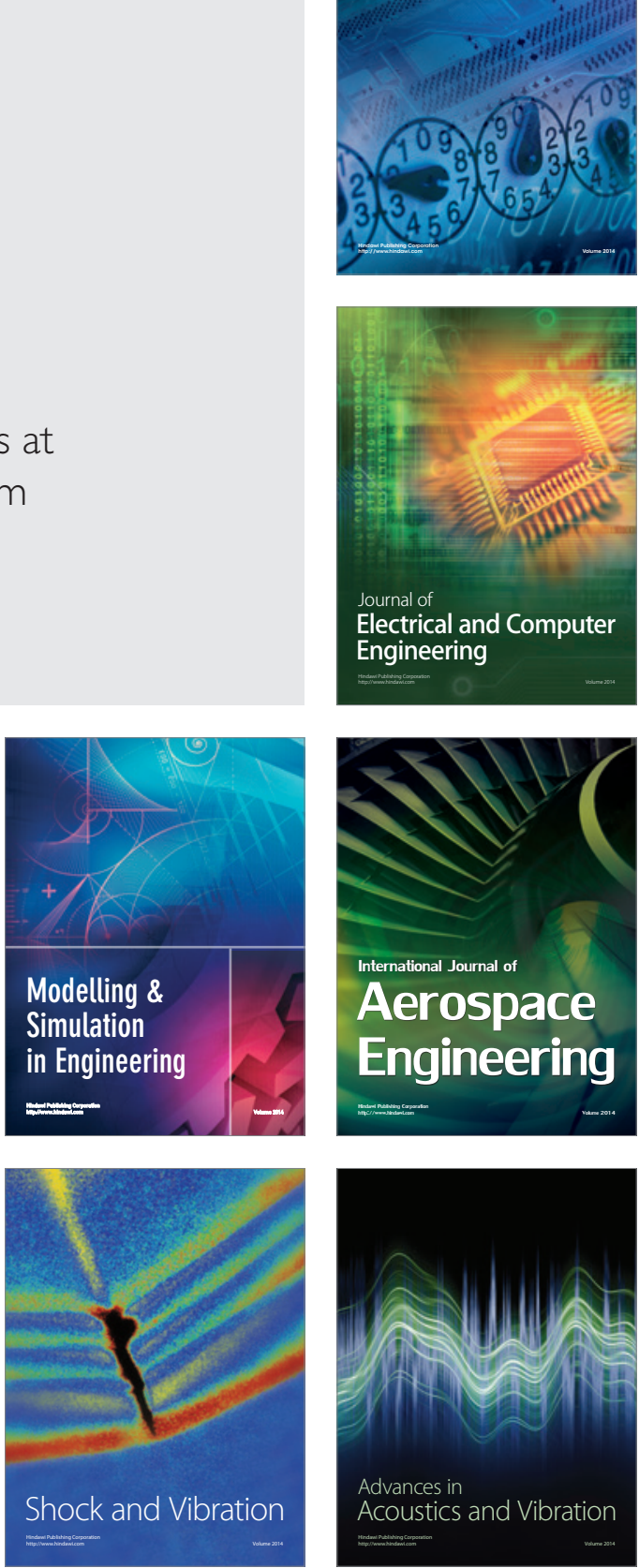